\title{
VERSITA
}

\section{LANDSCAPE ECOLOGY AND RURAL ROADS: TRAFFIC CALMING FOR IMPROVING BOTH LANDSCAPE AND WILDLIFE?}

\author{
CATHARINUS F. JAARSMA ${ }^{1 *}$, FRANK VAN LANGEVELDE ${ }^{2}$, RAOUL BEUNEN ${ }^{3}$ \\ ${ }^{1}$ Consultant, Associate Professor Land Use Planning (emeritus), Belmontelaan 5, 6703 EC Wageningen, The Ne- \\ therlands; e-mail: rinus.jaarsma@kpnmail.nl \\ ${ }^{2}$ Wageningen University, Resource Ecology group, P.O. Box 47, 6700 AA Wageningen, The Netherlands; e-mail: \\ frank.vanlangevelde@wur.nl \\ ${ }^{3}$ Wageningen University, Strategic Communication group, P.O. Box 8130, 6700 EW Wageningen, The Netherlands; \\ e-mail: raoul.beunen@wur.nl \\ *Author for correspondence
}

\begin{abstract}
Jaarsma C.F., van Langevelde F., Beunen R.: Landscape ecology and rural roads: Traffic calming for improving both landscape and wildlife? Ekológia (Bratislava), Vol. 32, No. 4, p. 352-360, 2013.

The concept of traffic calming has successfully improved road safety. This concept applied in rural areas has provided new insights in the mitigation of negative effects of roads and traffic. Earlier studies have shown that the concept, distinguishing between local access roads and rural arterial highways, can also improve landscape connectivity for wildlife. Physical speed-reducing devices are frequently used in the context of traffic calming, but applying these devices may negatively impact the coherence and identity of the landscape. Therefore an alternative approach for speed reduction has been proposed, namely applying local landscape elements (such as hedgerows), plantings and objects of cultural heritage (such as railings of small bridges over local water courses) as speed-reducing devices. We explain this 'green approach' with examples from Dutch practice. We conclude that a combination of disciplines is needed to realize this new approach, which may be more cost-effective than the traditional approach and additionally improve the landscape quality. The new insights are at least equally effective from a landscape ecological viewpoint.
\end{abstract}

Key words: connectivity; habitat fragmentation; landscape governance; rural transportation; traffic safety.

\section{Introduction}

Roads have several negative effects on nature, caused by the physical presence of the infrastructure and its traffic flows. Together, these effects could result in conditions where wildlife species are endangered and local populations might become extinct, which has been a major concern for society (Forman et al., 2003). Focusing on fauna, habitat fragmentation can be mitigated by improving the connectivity of the landscape through enlarging the habitat area of wildlife that can be accessed without level crossing of busy roads. Therefore, either of the two approaches can be applied - focusing on two-level crossings (wildlife overpasses or underpasses) or improving the opportunities for level-crossing (Seiler, 2002). To be effective, these approaches 
should be applied together on both major and minor roads in a sufficiently large rural area. The concept of traffic calming (TC), which originally has been developed to improve road safety, can be applied to improve connectivity when we combine these two approaches. This concept applied in rural areas has provided new insights in the mitigation of negative effects of roads and traffic (Van Langevelde, Jaarsma, 2009). So far the usual approach in TC has been mainly to focus on speed reduction on minor roads by means of physical devices such as speed humps and chicanes. However, from the viewpoint of landscape governance, the character of such 'built fabrics' decreases the coherence and identity of cultural and natural landscapes (Garré et al., 2009). Therefore, there seems to be a conflict between protecting landscape characteristics and improving ecological connectivity through the implementation of TC schemes.

We aim to show how new insights with an alternative approach of TC, with speed-reducing devices based on local landscape characteristics, such as hedgerows, plantings, and objects of cultural heritage, can be applied as a landscape policy instrument as well as an instrument to improve landscape connectivity for wildlife.

We therefore first present the ecological effects of different types of road infrastructure, followed by a section on 'traditional' rural TC with merely physical devices. We then present the 'green approach' as an alternative, with examples from the Dutch practice. Finally, we discuss the merits of this green approach.

\section{Road infrastructure and its ecological effects}

Ecological literature describes a wide range of effects of roads on nature, caused by the physical presence of the infrastructure and its traffic flows (Fig. 1). These ecological effects are generally classified into five major categories: (1) habitat loss (land uptake, habitat transformation); (2) roads and verges acting as corridors; (3) disturbance and edge effects (avoidance, pollution, increased predation); (4) barrier effects (by unsuitable habitat/disturbances, repelled by traffic or road characteristics, physical hindrances); and (5) traffic mortality.

The appearance of the effects in Fig. 1 depends on the characteristics of the road (i.e. profile and pavement) and its traffic flow (i.e. volume and speed). The usual classification for rural roads, distinguishing between motorways, rural arterial highways (RAHs) and minor rural roads (MRRs) can be helpful for this purpose. Motorways have a wide profile (and so large land uptake), high volumes (and so large disturbance and avoidance effects) and consequently form an absolute barrier for many species. On a somewhat smaller scale the same holds for RAHs. Contrasting with both types of major roads, MRRs are much smaller in width and designed to carry lower volumes, making traffic mortality a major ecological effect for most species (Van Langevelde et al., 2009). Another relevant difference between major and minor road networks is their length. In the Netherlands, motorways cover about $2300 \mathrm{~km}$, RAHs $7500 \mathrm{~km}$ and paved public MRRs 47,650 km. Laying out these total lengths in a regular square grid, the mesh width of the three road types are respectively $25.8 \mathrm{~km}, 8.2 \mathrm{~km}$ and $1.3 \mathrm{~km}$. Mesh width is an indication for the distances an animal can move through the landscape without crossing a road (Van Langevelde et al., 2009). Consequently, the mitigation of habitat fragmentation by improving the connectivity of the landscape also depends on road category.

Habitat fragmentation can be mitigated with two types of approaches that can enhance landscape connectivity for wildlife: (1) to prevent wildlife from entering the road by fencing 


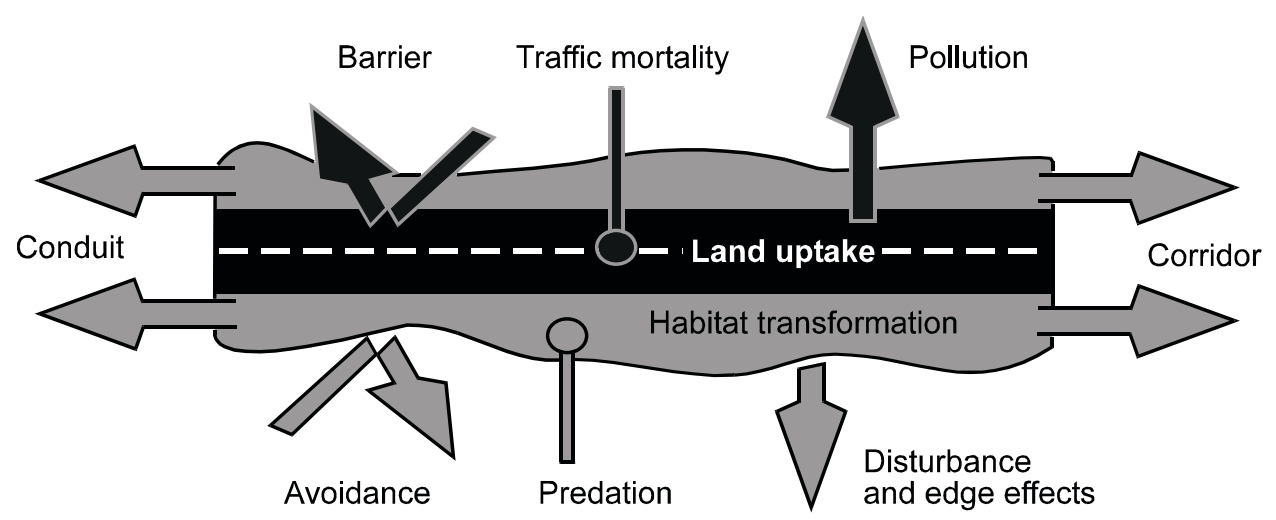

Fig. 1. Schematic representation of the five direct ecological effects of road infrastructure (Seiler, 2002).

in combination with two-level crossings (overpasses and underpasses) and (2) to improve the opportunities for level-crossing by reducing traffic volumes and/or speeds. For motorways and RAHs the first approach is generally applied. The second approach is more realistic for minor roads, the most occurring roads in a rural area. The mere thought of their length in combination with the frequent accesses to buildings and farmland prohibits fencing alongside these roads. Moreover, applying one approach to reduce the effects of one road type is not sufficient as the networks of minor and major roads act together as a single road infrastructure system. To be effective, the approaches for mitigating habitat fragmentation should therefore be applied together on the entire road network in a sufficiently large area. In an earlier study, thresholds for the size of traffic-calmed areas and remaining traffic volumes on minor access roads that may allow persistent populations have been derived using metapopulation theory (Van Langevelde, Jaarsma, 2009).

\section{Traffic calming (TC)}

The concept of TC has been developed since the 1970s to improve road safety. The impact of TC on road safety is based on considerable differences in accident rates (victims per kilometre travelled) between arterial highways and minor roads. TC started in urban areas (Kjemtrup, Herrstedt, 1992), but later it had been proposed for rural areas as well (Jaarsma, 1997). TC aims at a concentration of diffuse flows of through traffic in an area on a limited number of roads around the traffic-calmed area, in conjunction with a reduction of both vehicle speeds and volumes within the traffic-calmed area. TC therefore differentiates between (1) roads for access only with low volumes and modest speeds within a traffic-calmed area and (2) flow roads located around this area, fitted to deal with somewhat higher volumes and speeds for through traffic in bundled traffic flows. This principle can be applied on different spatial scales, as Fig. 2 shows schematically for an area with a regular square grid. Speed reduction on access roads is a condicio sine qua non in this context. Vehicle speed decides travel time, and, as such, is an important variable for route choice 
by a driver. To tempt drivers to use safer RAHs instead of access roads is therefore closely related to somewhat longer travel times on access roads. It is because of this reason that physical speedreducing measures on access roads are widely applied, such as speed humps, raised level-crossings and chicanes. From the viewpoint of landscape governance, most of such physical measures decrease landscape quality, because they do not fit in the 'natural landscape'.

(a)

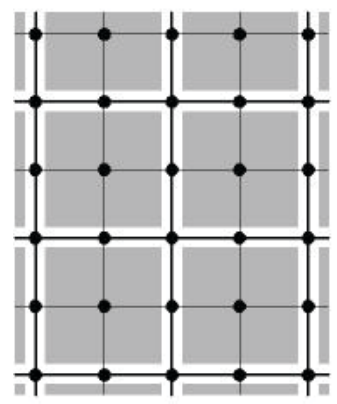

— road link with flow function (b)

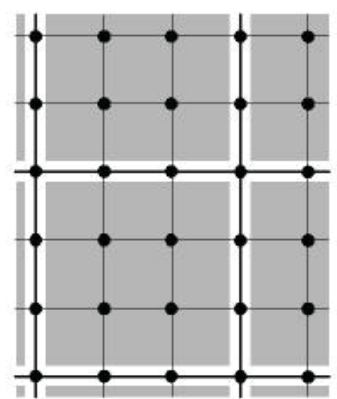

road link with access function (c)

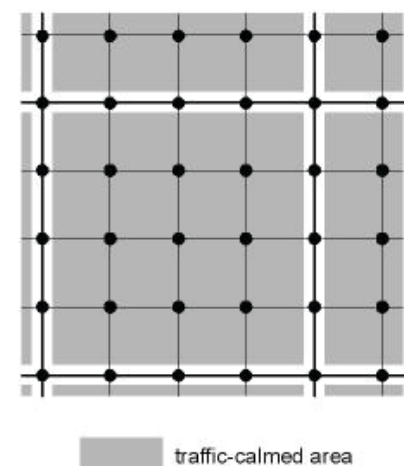

Fig. 2. A rural road network schematically represented in a regular square grid with two types of roads (roads with a local access function and roads with a flow function for through traffic) and different sizes of the traffic-calmed areas (Van Langevelde, Jaarsma, 2009).

Urban TC in continental Europe was developed to obtain speed reduction of vehicles, but it is evolved into a concept with a much wider definition, including physical planning and environmental objectives (Hass-Klau et al., 1992). Rural TC can also be applied in a broader context 'to find the right balance between maximizing accessibility and opening-up on one hand and minimizing traffic unsafety, noise and pollution as well as habitat fragmentation for the fauna' (Jaarsma, 1997). This wider approach 'connects' TC in transportation planning with habitat defragmentation in landscape ecology by enhancing connectivity for wildlife. Figure 2 illustrates the enhanced connectivity for wildlife because of larger continuous areas with lower volumes, be it depending on both scale (i.e. the size) and efficiency (i.e. the part of the original volume that still uses the original route on the access road) of the traffic-calmed area. Although the RAHs with higher volumes still act as barriers, their number is limited and preferably these flow roads do not give direct access to houses and agricultural fields. Therefore, fencing in combination with twolevel crossings may become a realistic option for these roads.

Traffic calming has widely been applied in the Netherlands since the mid-1990s as a part of the 'sustainable road safety policy' (Wegman, Aarts, 2006). This policy has been very successful: the number of people killed in traffic accidents decreased from 1334 in 1995 to 546 in 2011 (SWOV, 2012). The dark side of this success, however, is the physical measures for speed reduction on MRRs, which are generally considered to decrease landscape quality. More specifically, uniform physical interventions to enforce desired car driving behaviour on MRRs may affect the road environment and reduce the landscape quality. Hence the implementation of a TC scheme may lead to a 'conflict': improving road safety as well as ecological connectivity at the cost of landscape quality. 


\section{Traffic calming: The proposed green approach}

\section{Ideas behind the green approach}

Starting with the idea that sustainable safety, including TC and speed reduction on MRRs, can also be realized with small physical interventions (i.e. road paintings, signs, humps and gates), the "Picture Book Minor Rural Roads" (CROW, 2008) has been developed. This Picture Book's purpose is to reach the desired traffic behaviour within the natural environment of the MRR in question. The Picture Book is not intended as an instruction handbook with mandatory guidelines for design, but as an inspiring tool, aiming to show how landscapefriendly measures and road safety can be combined in a 'green approach'. A combination of knowledge from several professional disciplines should be applied for this purpose: spatial planners, landscape architects, psychologists, ecologists and - last but not least - transportation engineers.

The green approach focuses on minor access roads with mixed traffic in traffic-calmed rural areas. Such areas are multifunctional, serving functions such as residence, outdoor recreation, agriculture, nature etc. This calls for an approach different from the traditional one in transportation engineering with a one-sided focus only on roads and vehicles. Within a traffic-calmed area, cars should not be leading for road design. Present and historic landscape elements in the road's surrounding should be considered for a role in the desired speed reduction. Such a 'self-explaining road' (Vester, Veenstra, 2007) may even improve landscape quality, with the MRR becoming an integral part of the landscape instead of a traffic lane.

Rows of trees, dikes and ditches can accentuate the course of a road, and roads can appear to have small widths by planting 'non-crash aggressive' overgrowth closer to the pavement (in the 'free of obstacles' zone) or by mowing the grass in the verges less frequently. This might prevent drivers from speeding. A similar effect might be reached by narrowing the lanes in combination with paved shoulders or by railings of small bridges where MRRs cross local watercourses. However, these examples should be applied with care in tailor-made designs because they are often, but not always, effective (CROW, 2008).

The green approach and landscape ecology

As said, TC has been introduced to improve traffic safety. However, there is a 'connection' between landscape ecology and TC. TC provides an enhanced connectivity for wildlife by larger continuous areas with only access roads with lower volumes (Fig. 2). Lower volumes and reduced speed levels decrease traffic mortality and in some situations may allow reduction of the pavement width of MRRs, to enlarge their verges and/or to introduce plantings. Road verges and plantings alongside MRRs are also important from a landscape ecological view, especially in large-scale agricultural areas, as they increase the role of roads as corridors (Van der Ree, Bennett, 2003; Van der Ree et al., 2010).

Considering the road from a landscape ecological viewpoint, the smaller the pavement width the better, especially for land uptake, barrier effect and traffic mortality effects (Fig. 1). TC decreases volumes and speeds within the traffic-calmed area and therefore on some road 
links, it may result in a reduction of pavement width. Paved shoulders or an unpaved middle of the road instead of the usual pavement for the full width of the MRR increases the possibilities of crossing the road, especially for small animals (Schatt, 1988).

\section{Examples of the proposed green approach}

We can provide some examples of the green approach from the 'Zak van Zuid-Beveland' in the province of Zeeland. This area is assigned as Dutch National Landscape and it shows a variety of landscape types. It is attractive for recreation, preferably on bicycle, but it also contains agricultural production area. Despite the presence of a network of major roads, the MRRs frequently suffer from rat run traffic. To improve traffic safety as well as the attractiveness of the area, plans for TC have been developed. Following the ideas suggested in the Picture Book (CROW, 2008), measures are based on the surrounding landscape keeping in mind the local culture heritage. Therefore a distinction has been made between three types of landscape: (1) 'old land' with creek ridges and slough areas, (2) 'new land polders' with roads on dikes and (3) 'renaissance polders' with long stretches of roads (Van Blerck et al., 2009).

For the re-design of roads within the 'old land' landscape, two types of MRRs have been distinguished: (1) winding historic roads on creek ridges and (2) recently new constructed straight roads in the historically road-less slough areas. Alongside the first type a hedgerow can be planted (Fig. 3), accentuating the contrast with the more 'open' roads with herbaceous verges in the slough area (Fig. 4).

Roads as in Figs 3 and 4 are intended for pedestrians, cyclists and agricultural vehicles. Their volumes allow for a construction of a so-called track road, with two single paved tracks instead of a pavement over the full width of the road (Fig. 5).
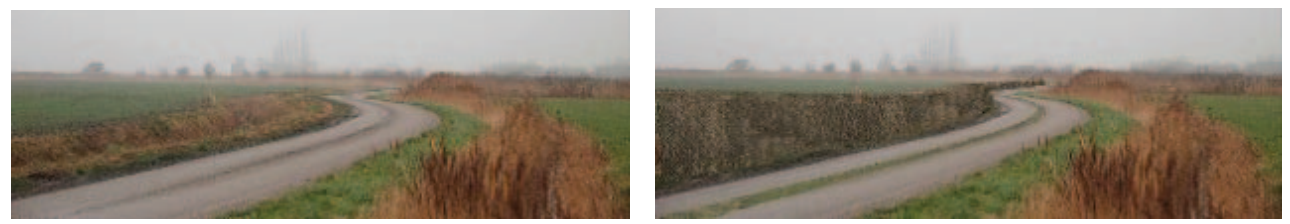

Fig. 3. Road on a creek ridge with a protected area for meadow birds on the right-hand side. Left: Present situation. Right: On the left-hand side the planting of a brushwood hedgerow is proposed. On the right-hand side the verge and the ditch will be managed as reed vegetation, to be mowed in a cycle of 4 years (Van Blerck et al., 2009).
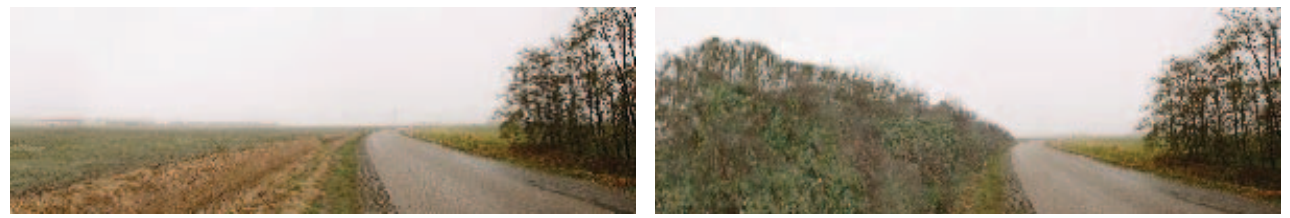

Fig. 4. Road on a creek ridge bending to the right into a recently constructed road through the slough area. Left: Present situation. Right: The proposal is to plant a brushwood hedgerow in the left-hand verge till the bend, where the road continues in an open area (Van Blerck et al., 2009). 
In the 'new land polders' three types of roads have been distinguished: (1) roads on dikes connecting villages, (2) other roads on dikes and (3) roads not situated on dikes. For the first type, a safe and comfortable connection for cars is combined with the typical character of a dike road by constructing a bicycle path on the foot of the dike and brushwood plantings (Fig. 6). For the other two types, their characteristics, as a dike road or an open road respectively, are accentuated.

Specific attention is needed for connecting the different types of road. The idea for such locations is to accentuate the differences in road character instead of 'flattening' them (Fig. 7).

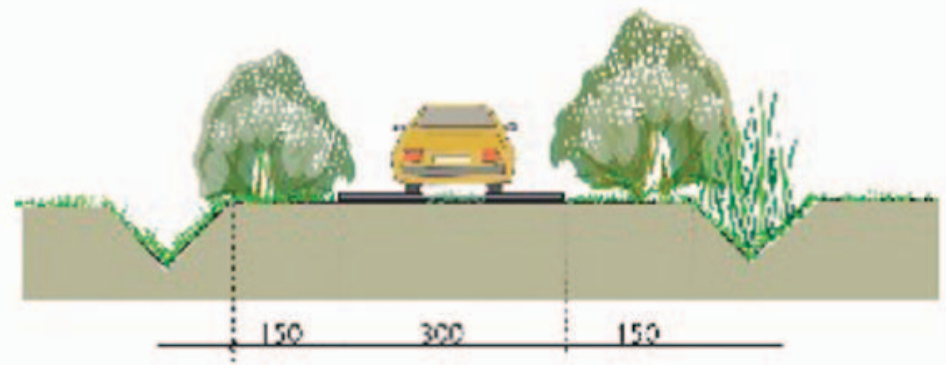

Fig. 5. Cross section of a 'track road': two paved tracks divided by a strip of grass (Van Blerck et al., 2009).

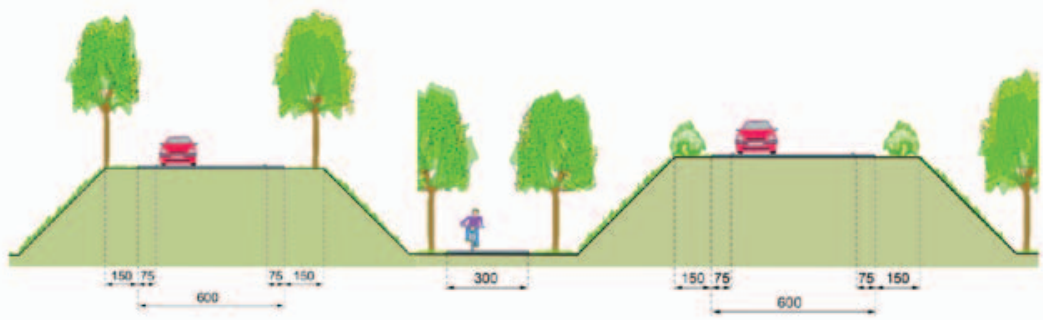

Fig. 6. Cross section of a dike road connecting villages. Left: Present situation. Right: Proposed situation with a bicycle path and brushwood plantings (Van Blerck et al., 2009).
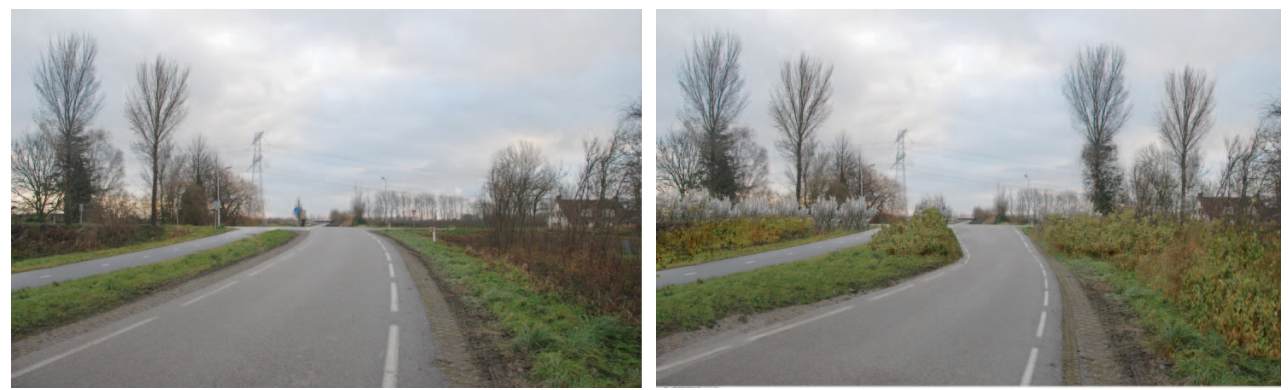

Fig. 7. Dangerous intersection of a road not situated on a dike with a dike road (on the background). Left: In the present situation the road in front leads fluently to the dike road, making the dike invisible. Right: The proposed solution is to accentuate the characteristics of the dike road by planting trees on the dike and a less fluently bend with a sharper slope of the other road (Van Blerck et al., 2009). 


\section{Discussion and conclusions}

In the past, TC has been developed as a successful tool for improving rural traffic safety, but the accompanying physical-technical devices to reduce speed in a rural area might impact landscape quality in a negative way. The examples in this paper illustrate the possibilities of a 'green approach' for speed reduction on MRRs, which can improve landscape quality as the planned changes agree with landscape elements that can be found in these historic landscapes. This 'green approach' focuses on the development of a plan that envisions a future spatial structure that relates road design to other land uses and regards the road as an element of the coherent landscape. The examples show that measures to improve road safety can be designed in such a way that they enhance the coherence and identity of landscape structures and elements. Measures such as adapting verges or plantings may improve habitat quality for both plants and animals and thus further strengthen the connectivity for wildlife with less traffic kills as realized in the 'traditional' TC (Van Langevelde et al., 2009; Van der Ree et al., 2010). TC in combination with an attractive landscape offers better opportunities for recreationists, especially those on feet or with a bicycle (Stevens, Slabbekoorn, 2001).

The cost-effectiveness ratio of a traffic safety measure gives insight into the costs invested to prevent one serious traffic casualty. For a zonal rural TC its value has been calculated on $€ 33,000$, which is a considerably lower amount than needed for comparable traffic safety measures (Jaarsma et al., 2011). Specific data for the green approach are not available yet. It is plausible, however, that for the same impact, i.e. speed reduction on MRRs and concentration of flows on RAHs, in the green approach even lower ratios will be found. Expensive technical interventions are avoided in the green approach and measures such as a smaller pavement width, paved shoulders and less mowing of the verge reduce maintenance costs (CROW, 2008; Vester, Veenstra, 2007).

The proposed green approach of TC requires a multidisciplinary approach in all stages of planning, from policy development in the beginning through the designs (as in Figs. 3 through 7) and the final phase of maintenance and monitoring. Traditional sectoral planning practices are not yet adapted to such an approach. Usually, transportation planning for improving road safety, planning for habitat de-fragmentation for wildlife and planning for rural recreation follow their own ways in different procedures. To change these practices, planning should take the form of policy integration and include planning as design (Van Assche et al., 2013). However, for planning to be effective it should focus on a sufficiently large area where the different roles of RAHs as well as MRRs are considered in relation to each other in a single road network. The Picture Book (CROW, 2008) aims to inspire the creativeness of transportation planners to use an integrated region-wide approach with cooperation of all relevant disciplines and stakeholders.

In conclusion, the concept of rural TC has been very successful in improving road safety and nowadays it is proposed to mitigate fragmentation of wildlife habitat. However, the mere application of technical-physical devices to reduce traffic speeds in rural areas is considered to decrease landscape quality. We show new insights with a 'green approach', applying local landscape characteristics for speed reduction of cars, allowing for improving landscape quality with the MRR becoming an integral part of the landscape instead of a traffic lane. We ar- 
gue that this 'green approach' is also beneficial for wildlife conservation as well as recreation, and it may even be more cost-effective than the traditional approach. To create such win-win situations, integrated planning procedures should take the place of the current sectoral planning approaches.

\section{Acknowledgements}

The authors thank Henk van Blerck, bureau Schokland, for providing the materials for Figures 3 through 7.

\section{References}

CROW, (2008). Rural Roads Nice and Safe. A Picture Book (in Dutch). Publication 259. Ede, the Netherlands.

Forman, R.T.T., Sperling, D., Bissonette, J.A., Clevenger, A.P., Chutshall, C.D., Dale, V.H., Fahrig, L., Goldman, C.R., Heanue, K., Jones, J.A., Swanso, F.J., Turrentine, T. \& Winter T.C. (2003). Road ecology. Science and solutions. Washington: Island Press.

Garré, S., Meeus, S. \& Gulinck H. (2009). The dual role of roads in the visual landscape: A case-study in the area around Mechelen (Belgium). Landsc. Urban Plann., 92, 125-135. DOI: 10.1016/j.landurbplan.2009.04.001.

Hass-Klau, C., Nold, I., Bocker, G. \& Crampton G. (1992). Civilised streets - A guide to traffic calming. Brighton: Environment and Transport Planning.

Jaarsma, C.F. (1997). Approaches for the planning of rural road networks according to sustainable land use planning. Landsc. Urban Plann., 39(1), 47-54.

Jaarsma, C.F., Louwerse, R., Dijkstra, A., de Vries, J.R. \& Spaas J.P. (2011): Making minor rural road networks safer: The effect of 60 km/h-zones. Accid. Anal. Prev., 43(4), 1508-1515. DOI: 10.1016/j.aap.2011.03.001.

Kjemtrup, K. \& Herrstedt L. (1992). Speed management and traffic calming in urban areas in Europe: a historical view. Accid. Anal. Prev., 24(1), 57-65.

Schatt, H. (1988). Planning and evaluation of rural road construction illustrated by Bavarian land consolidation schemes. In Th. Michels \& C.F. Jaarsma (Eds.), Minor rural roads. Planning, design and evaluation (pp. 39-46). Wageningen: Pudoc.

Seiler, A. (2002). Effects of infrastructure on nature. In Anonymus, COST 341. Habitat fragmentation due to transportation infrastructure. The European Review (pp. 31-50). Brussels: European Commission, Directorate-General for Research.

Stevens, C. \& Slabbekoorn K. (2001). Van plattelandsweg tot fietsweg. Verkeerskunde, 52(5), 48-52.

SWOV (Road Safety Research Institute) (2012). Registered numbers of traffic kills in the Netherlands. Data on www. swov.nl/ibmcognos/cgi-bin (accessed 12 September 2012).

Van Assche, K., Beunen, R., Duineveld, M. \& de Jong H. (2013). Co- evolutions of planning and design: Risks and benefits of design perspectives in planning systems. Planning Theory, 12(2): 177-198. DOI: $10.1177 / 1473095212456771$.

Van Blerck, H.J.J.C.M., Hauptmeijer W. \& Slabbekoorn C. (2009). Duurzaam Veilig in een Nationaal Landschap. $15 \mathrm{e}$ Verkeerskundige Werkdagen, CROW.

Van der Ree, R. \& Bennett A.F. (2003). Home range of the squirrel glider (Petaurus norfolcensis) in a network of linear habitats. J. Zool. (Lond.), 259, 327-336. DOI: 10.1017/S0952836902003229.

Van der Ree, R., Cesarini, S., Sunnucks, P., Moore, J.L. \& Taylor A. (2010). Large gaps in canopy reduce road crossing by a gliding mammal. Ecology and Society, 15(4), 35. http://www.ecologyandsociety.org/vol15/iss4/art35/

Van Langevelde, F., van Dooremalen, C. \& Jaarsma C.F. (2009). Traffic mortality and the role of minor roads. J. Environ. Manag., 90, 660-667. DOI: 10.1016/j.jenvman.2007.09.003.

Van Langevelde, F. \& Jaarsma C.F. (2009). Modelling the effect of traffic calming on local animal population persistence. Ecology and Society, 14(2), 39. http://www.ecologyandsociety.org/vol14/iss2/art39/

Vester, A.J. \& Veenstra H. (2007). Natuurlijk sturen. Groen, 63(11), 18-21.

Wegman, F. \& Aarts L. (Eds.) (2006): Advancing sustainable safety. National road safety outlook for 2005-2020. Leidschendam: SWOV Institute for Road Safety Research. 